\title{
Cobalt Oxide Nanoparticles: Characterization and its Electrocatalytic Activity towards Nitrobenzene
}

\author{
R. MANIGANDAN ${ }^{\mathrm{a}}, \mathrm{K}$. GIRIBABU ${ }^{\mathrm{a}}, \mathrm{R}$. SURESH ${ }^{\mathrm{a}}$, \\ L. VIJAYALAKSHMI ${ }^{b}$, A. STEPHEN ${ }^{\mathrm{c}}$ and V. NARAYANAN ${ }^{\mathrm{a} *}$
}

${ }^{a}$ Department of Inorganic Chemistry, University of Madras, Guindy Campus, Chennai- 600025, India

bVidhya Sagar Women's College, Chengalpattu, Kancheepuram - 603211, India

${ }^{\mathrm{c}}$ Department of Nuclear Physics, University of Madras, Guindy Campus, Chennai- 600025, India

vnnara@yahoo.co.in

Received 19 January 2013 / Accepted 15 February 2013

\begin{abstract}
Cobalt oxide $\left(\mathrm{Co}_{3} \mathrm{O}_{4}\right)$ nanoparticles were successfully prepared by thermal decomposition of cobalt hydroxide synthesized from cobalt acetate, ammonium hydroxide and $10 \%$ glycerol. The cobalt oxide nanoparticles calcined at $450{ }^{\circ} \mathrm{C}$ were characterized by using XRD. The XRD confirms the crystallinity and crystal structure of the sample. It also shows that the diffraction peak are broadened which reveals the narrow size distribution of the cobalt oxide nanoparticles. In addition, the average grain size, lattice parameter values also calculated using XRD. The FT-IR analysis confirms the functional group presents in the cobalt oxide nanoparticles. The SEM image of cobalt oxide nanoparticles shows the nanosized agglomerated particles. The electrochemical detection of nitrobenzene (NB) by cobalt oxide nanoparticles was investigated by cyclic voltammetry. The result concludes that the cobalt oxide nanoparticles have higher activity for the detection of nitrobenzene.
\end{abstract}

Keywords: Cobalt oxide, Thermal decomposition, Cyclic voltammetry, Nitrobenzene.

\section{Introduction}

Nanostructured materials have been widely investigated for the fundamental scientific and technological interests in accessing new classes of functional materials with unprecedented properties and applications ${ }^{1-3}$. In recent years, there has been an increasing interest in the synthesis of nanosized crystalline metal oxides because of their large surface areas, unusual adsorptive properties, surface defects and fast diffusivities. $\mathrm{Co}_{3} \mathrm{O}_{4}$ is a very important material extensively used in catalysis, gas sensors, electrochromic films, battery cathodes, heterogeneous catalytic materials and magnetic materials ${ }^{4,5}$. Due to their small size, nanoparticles exhibit novel material properties that are significantly different from those of their bulk counterparts. $\mathrm{Co}_{3} \mathrm{O}_{4}$ nanoparticles have been synthesized by various methods like sol-gel, surfactant-mediated synthesis, thermal decomposition, polymer-matrix assisted

†Presented to the National Conference on Chemistry Solutions at SRM University, India 
synthesis and spray-pyrolysis ${ }^{6,7}$. Some of the above methods suffer from the difficulty in size-homogeneity and well dispersion of $\mathrm{Co}_{3} \mathrm{O}_{4}$ nanoparticles. Recently, several methods have been developed to prepare ultrafine $\mathrm{Co}_{3} \mathrm{O}_{4}$ powder, including low pressure spray pyrolysis, optical gas sensors, antiferromagnetic layers, solar thermal absorbers, etc. In this study, we have reported the synthesis of $\mathrm{Co}_{3} \mathrm{O}_{4}$ nanoparticles using thermal decomposition method and characterized its structural, morphological properties. Additionally we have performed the electrocatalytic activity of the synthesized $\mathrm{Co}_{3} \mathrm{O}_{4}$ towards the detection of NB.

\section{Experimental}

Cobalt chloride hexahydrate $\left(\mathrm{CoCl}_{2} \cdot 6 \mathrm{H}_{2} \mathrm{O}\right)$, nitrobenzene, ammonium hydroxide, potassium hydroxide and glycerol were purchased from Qualigens. Double distilled water was used as the solvent throughout the experiment.

\section{Characterization methods}

The crystal structure of $\mathrm{Co}_{3} \mathrm{O}_{4}$ nanoparticles was analyzed by a Rich Siefert 3000 diffractometer with $\mathrm{Cu}-\mathrm{K} \alpha_{1}$ radiation $\left(\lambda=1.5406 \AA\right.$ ). FT-IR spectrum of the $\mathrm{Co}_{3} \mathrm{O}_{4}$ was recorded on Schimadzu FT-IR 8300 series instrument by using potassium bromide pellets. The morphology of the materials was analyzed by SEM HITACHI SU6600 scanning electron microscopy respectively. The electrochemical experiments were performed on a CHI 600A electrochemical instrument using the as-modified electrode and bare GCE as working electrode, a platinum wire was the counter electrode, and saturated calomel electrode (SCE) was the reference electrode.

\section{Synthesis of $\mathrm{Co}_{3} \mathrm{O}_{4}$ nanoparticles}

$\mathrm{Co}_{3} \mathrm{O}_{4}$ was prepared by thermal decomposition of cobalt hydroxide. The cobalt hydroxide was prepared by reacting aqueous solutions of $0.01 \mathrm{M}$ cobalt chloride and $0.01 \mathrm{M}$ ammonium hydroxide. The $0.01 \mathrm{M}$ cobalt chloride was dissolved in $500 \mathrm{~mL}$ distilled water and $10 \%$ of glycerol. This suspension was stirred for $20 \mathrm{~min}$ at $50{ }^{\circ} \mathrm{C}$ in magnetic stirrer. After $20 \mathrm{~min}$, the dissolved ammonium hydroxide solution $(50 \mathrm{~mL})$ was slowly added to control the agglomeration. The obtained cobalt hydroxide is calcined in air for $3 \mathrm{~h}$ at $450{ }^{\circ} \mathrm{C}$, which results the $\mathrm{Co}_{3} \mathrm{O}_{4}$ nanoparticles.

\section{Electrode modification}

Ultrasonically dispersed $\mathrm{Co}_{3} \mathrm{O}_{4}$ nanopowder in $5 \mathrm{~mL}$ of water was drop coated onto the GCE and dried at room temperature. The $\mathrm{Co}_{3} \mathrm{O}_{4}$ coated electrode prepared by electrochemical deposition techniques and used for electrocatalytic reduction of nitrobenzene. CV's were run in electrochemical cell containing $50 \mathrm{~mL}$ DD water and $0.1 \mathrm{M} \mathrm{KOH}$ in presence of SCE reference electrode and Pt wire as counter electrode.

\section{Results and Discussion}

Structure and morphology

XRD patterns of the $\mathrm{Co}_{3} \mathrm{O}_{4}$ nanoparticles calcined at $450{ }^{\circ} \mathrm{C}$, is shown in Figure 1, which indicates the cobalt oxide has cubic phase structure. The peak positions $\left(2 \theta=19.02^{\circ}, 31.3^{\circ}\right.$, $36.88^{\circ}, 38.59^{\circ}, 44.85^{\circ}, 59.41^{\circ}$ and $65.30^{\circ}$ ) and relative intensities obtained for the $\mathrm{Co}_{3} \mathrm{O}_{4}$ match with the JCPDS card No: 073-1701 file, identifying it as $\mathrm{Co}_{3} \mathrm{O}_{4}$ with a cubic structure with Fd-3m (227) space group and lattice constant $\mathrm{a}=8.08 \AA$. There was no characteristic peaks of impurity were observed. The average grain size of $\mathrm{Co}_{3} \mathrm{O}_{4}$ is determined using Scherrer relation, and it was found to be around $49 \mathrm{~nm}$.

FT-IR spectrum of $\mathrm{Co}_{3} \mathrm{O}_{4}$ nanoparticles (Figure 2) showed significant absorption peaks at 1607 and $525,647 \mathrm{~cm}^{-1}$. The absorption band at $525 \mathrm{~cm}^{-1}$ was assigned to Co-O stretching 
vibration mode ${ }^{8}$ and $647 \mathrm{~cm}^{-1}$ was assigned to the bridging vibration of $\mathrm{O}-\mathrm{Co}-\mathrm{O}$ bond ${ }^{9}$. The weak band near $1635 \mathrm{~cm}^{-1}$ is assigned to $\mathrm{H}-\mathrm{O}-\mathrm{H}$ bending vibration mode were presented due to the adsorption of moisture, when FTIR sample disks were prepared in an open air atmosphere. These observations provided the evidence for the presence of hydration in the structure ${ }^{10}$.

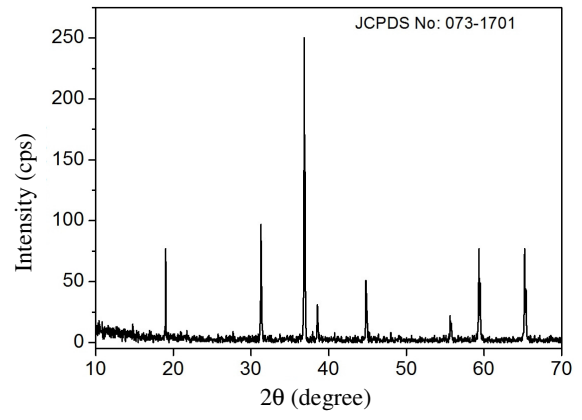

Figure 1. XRD pattern of the $\mathrm{Co}_{3} \mathrm{O}_{4}$ nanoparticles prepared at $450{ }^{\circ} \mathrm{C}$

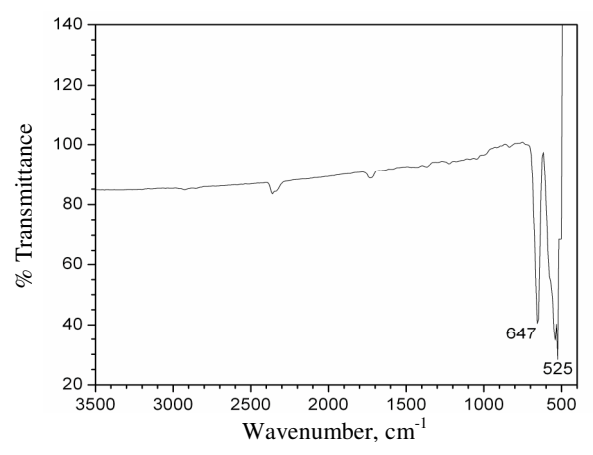

Figure 2. FT-IR spectrum of $\mathrm{Co}_{3} \mathrm{O}_{4}$

The SEM micrograph of the $\mathrm{Co}_{3} \mathrm{O}_{4}$ calcined at $450{ }^{\circ} \mathrm{C}$ is shown in Figure 3. It can be seen that the particles adopt irregular morphology with different sized particle. In addition, $\mathrm{Co}_{3} \mathrm{O}_{4}$ nanoparticles show rod shape with smooth surface. It clearly indicates the fine rod like particles adsorbed on the surface due to the aggregation. It shows the rod like agglomerates were purely due to the magnetic induction between the particles ${ }^{11}$.

\section{Electrochemical property}

The electrochemical behaviour of $1 \mathrm{mM} \mathrm{NB}$ at $\mathrm{Co}_{3} \mathrm{O}_{4} / \mathrm{GCE}$ was tested with cyclic voltammetric $(\mathrm{CV})$ measurements in $0.1 \mathrm{M} \mathrm{KOH}$. Figure $4 \mathrm{~b}$ shows the $\mathrm{CV}$ of $\mathrm{Co}_{3} \mathrm{O}_{4} / \mathrm{GCE}$ in $\mathrm{KOH}$ electrolyte. It can be seen that the $\mathrm{Co}_{3} \mathrm{O}_{4}$ is non-electroactive in the selected potential region. Figure $4 \mathrm{~b}$ shows broad peaks in the potential range from -0.4 to $-0.6 \mathrm{~V}$. Figure $4 \mathrm{~b}$ shows reduction of $\mathrm{NB}$ at $\mathrm{Co}_{3} \mathrm{O}_{4} / \mathrm{GCE}$. It shows the cathodic peak at $-0.8 \mathrm{~V}$ with enhanced current response relative to that of $\mathrm{Co}_{3} \mathrm{O}_{4} \mathrm{GCE}$. At the same time, we have noticed that the $\mathrm{Co}_{3} \mathrm{O}_{4} \mathrm{GCE}$ shows higher current response at the positive potential region 0 to $0.2 \mathrm{~V}$, which was indicative of the electron transport property of nitrobenzene. It indicated that the $\mathrm{Co}_{3} \mathrm{O}_{4}$ were catalytically more active toward electrochemical reduction of nitrobenzene to aniline ${ }^{12}$.

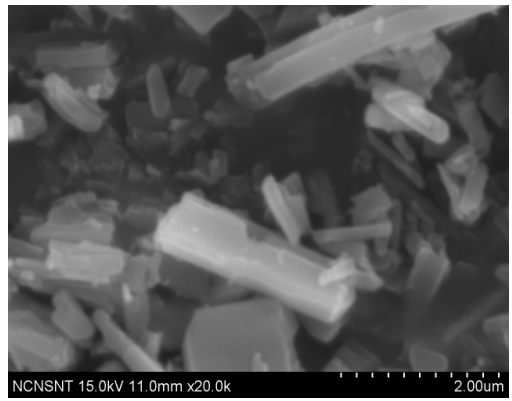

Figure 3. $\mathrm{SEM}$ image of $\mathrm{Co}_{3} \mathrm{O}_{4}$

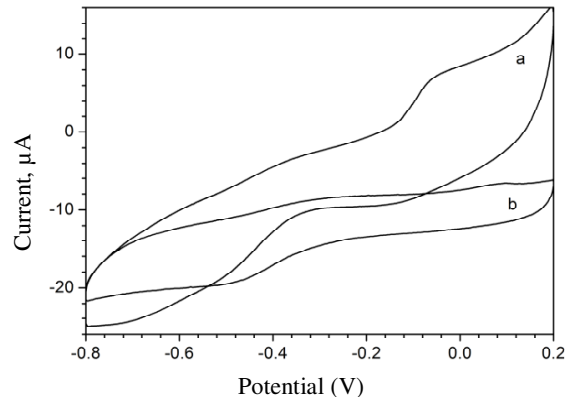

Figure 4. Cyclic voltammograms (CV) of (a) Cobalt oxide modified GCE (b) Bare GCE for the reduction of $0.001 \mathrm{M}$ nitrobenzene in $0.1 \mathrm{M}$ $\mathrm{KOH}$ electrolyte at $50 \mathrm{mVs}^{-1}$ 


\section{Conclusion}

The $\mathrm{Co}_{3} \mathrm{O}_{4}$ nanoparticles were prepared by thermal decomposition method. FT-IR analysis confirms the formation of the $\mathrm{Co}_{3} \mathrm{O}_{4}$ nanoparticles. The calcined cobalt oxide nanoparticles at $450{ }^{\circ} \mathrm{C}$ were characterized by using XRD. The XRD confirms the crystal structure and of the samples. The SEM of $\mathrm{Co}_{3} \mathrm{O}_{4}$ nanoparticles shows the spherical agglomerated particles. The optical absorption spectrum of cobalt oxide sample was studied by UV-Visible spectroscopy. The electrochemical detection of nitrobenzene by cobalt oxide nanoparticles was investigated by cyclic voltammetry. The results conclude that the cobalt oxide nanoparticles have higher activity for the detection of nitrobenzene.

\section{Acknowledgment}

One of the authors (RM) acknowledges the financial assistance and FESEM facility provided by the National Centre for Nanoscience and Nanotechnology, University of Madras.

\section{References}

1. Yu Lina, Ting Xie, Baochang Cheng, Baoyou Geng and Lide Zhang, Chem Phys Lett., 2003, 380, 521-525.

2. Manigandan R, Suresh R, Giribabu K, Vijayalakshmi L, Stephen A and Narayanan V, Adv Mater Res., 2012, 584, 263-266.

3. Amekura H, Umeda N, Takeda Y, Lu J and Kishimoto N, Appl Phys Lett., 2004, 85, 6.

4. Shiloms M I, Pshenichnikov A F, Morozov K I and Shurubor I Yu, J Magn Magn Mater., 1990, 85, 40-46.

5. Bergemann C, Muller-Schulte D, Oster J, Brassard L A and Lubbe A S, J Magn Magn Mater., 1999, 194, 45-52.

6. Gruttner C and Teller J, J Magn Magn Mater., 1999, 194, 8-15.

7. Guo L, Huang J, Li X Y and Yang S H, Phys Chem Chem Phys., 2001, 3, 1661-1665.

8. Estepa L and Daudon M, Biospectroscopy, 1997, 3, 347-369.

9. Wu S H and Chen D H, J Colloid Interface Sci., 2003, 259, 282-286.

10. Xing W, Li F, Yan Z and Lu G Q, J Power Sources, 2004, 134, 324-330.

11. Koutzarova T, Kolev S, Ghelev C, Paneva D and Nedkov I, Phys Stat Sol (c)., 2006, 3, 1302-1307.

12. Radhakrishnan S and Deshpande S D, Mater Lett, 2001, 48, 144. 